\title{
Literaten als Chronisten der Sprache Am Beispiel von Arno Schmidt und Botho Strauß
}

\author{
Henne, Helmut
}

Veröffentlicht in:

Jahrbuch 1992 der Braunschweigischen Wissenschaftlichen Gesellschaft, S.113

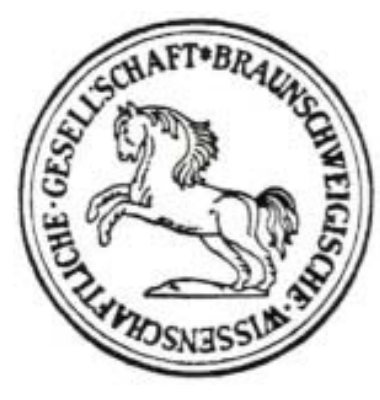

Verlag Erich Goltze KG, Göttingen 
Helmut Henne, Wolfenbüttel

\title{
Literaten als Chronisten der Sprache Am Beispiel von Arno Schmidt und Botho Strauß
}

\author{
Braunschweig, 14. März 1992*
}

Zusammenfassung: Mit dem Ende der Nachkriegszeit und der Vereinigung der beiden deutschen Teilstaaten wurde die Gegenwart vor unseren Augen historisch. Eine deutsche Sprachgeschichte der Nachkriegszeit, die nunmehr zu konzipieren und zu verfassen ist, darf literarische Quellen, die sich auch als Chroniken verstehen, nicht übergehen. Hierzu zählt das Werk von Arno Schmidt und Botho Strauß. Am Beispiel von Arno Schmidts „Leviathan oder Die beste der Welten“ (1949) und Botho Strauß „Paare, Passanten“ (1981) wird die zeitgeschichtliche Authentizität dieser Texte und ihre chronikalische Qualität herausgearbeitet.

Das soll hier an zwei Beispielen dargestellt werden: Im Text von Arno Schmidt wird gleich zu Anfang ein Werbespruch der Zeit - die Handlung spielt im Februar 1945 zitiert (,Millionen tragen Greiff-Kleidung“), der eine fatale Semantik entfaltet: Die „Blauleinenanzüge der Schlosser“ aus den Greiff-Werken in Greiffenberg in Schlesien sind auch Symbol für den Griff von Millionen Deutschen nach Leben und Besitz ihrer Nachbarn.

,,Zum Kottbusser Tor!' riefen sich die versprengten Demonstranten zu, und einige nahmen die U-Bahn. Aber nein, hier muß ich umkehren. Kann nicht Mitläufer bei den Jungen sein", heißt es bei B. Strauß. Das Reizwort "Mitläufer" verbindet die Menschen von 1945, die nun selbst auf der Flucht sind, und die Demonstranten der 70er Jahre. Diese streben dem ,Tor“ zu, das für Offenheit und Freiheit steht. Dieser Verlokkung versagen sich „einige“, die die „U-Bahn“ nehmen. Die tiefere Bedeutung dieses Wortes liest man natürlich mit: „U“ steht für Untergrund, in den die Demonstranten, z.B. als terroristische Gruppe, abtauchen.

„Empfindliche Chronisten“ (B. Strauß) sind gute Schriftsteller allemal. Ihre Texte sind literarische Chroniken, die insofern auch Quellen der Sprachgeschichte sind. Die systematische Analyse und Interpretation legt das bloß.

\footnotetext{
* Vortrag vor der Klasse für Geisteswissenschaften der Braunschweigischen Wissenschaftlichen Gesellschaft (Zusammenfassung).
}

Der Text des Vortrags wird publiziert in der Festschrift für Peter v. Polenz. Berlin. New York: de Gruyter 1993 